\title{
The Role of Technology as an Enabler in Job Redesign
}

\author{
David M. Savino '
}

\begin{abstract}
This paper is an acknowledgement of the role of technology as an enabler that encourages the constant need to evaluate, update and employ changing job descriptions and business processes that truly acknowledge job requirements as they are versus notions of what they have been or should be. Advancements in technology have brought about a significant amount of change in terms of how we go about doing our daily work. The evolution from being a manufacturing economy to being information and service based brought to the workplace new realities and responsibilities. As a result, workers can no longer expect to be given a specific listing of assigned duties and tasks that remain fixed over a long period of time. The new paradigm in the workplace relies on continuous demands for improvement and acquired knowledge in a dynamic environment. The catalyst that enables continuous improvement is technology.
\end{abstract}

Key Words: Job and work redesign; business process reengineering; information technology; change management

\footnotetext{
' Ohio Northern University. 218 Dicke Hall. James F. Dicke College of Business Administration. Ada, Ohio 458I0. (419) 772-2077 (phone) (419) 772-3I25 (fax) d-savino@onu.edu
}

ISSN: 07I8-2724. (http://www.jotmi.org)

Journal of Technology Management \& Innovation (C) Universidad Alberto Hurtado, Facultad de Economía y Negocios 


\section{Introduction}

It is now obvious that the established paradigms of business and economic structures appear to be grossly inadequate in dealing with the challenges of the twenty-first century. One-by-one many of the processes that have been firmly in place at least since the Great Depression have fallen by the wayside or have proven to be extremely ineffective in guiding decisions in our business and economic systems. Recent difficulties and failings in our financial and traditional manufacturing systems point to the need for some form of intervention by the government to create new and enduring paradigms, much of which may be needed and at the same time greatly unwelcome. It has become very apparent that significant changes in both our overall economy as well as with business practices need to be instituted to successfully face severe future challenges.

While past incremental procedural and technological changes were sufficient for sustaining the system they were inadequate in paving the way to clear and comprehensive solutions. It is therefore not all that surprising that the incremental introduction of technological innovation over the decades has failed to allow organizations to break away from systems, beliefs and objectives that no longer prevail (Hammer, 1990). As the first decade of the new century comes to a close there is a pervasive uncertainty that calls for an acknowledgement of the need to understand and address critical system design issues. For much of the past two decades the efforts devoted to such concepts as Total Quality Management (TQM) and Business Process Reengineering (BPR) have been an attempt to change or shift the overriding paradigm of sameness and the safety of predictability. While both methods have proven the ability to lead to the desired results of more efficient business practices and more competitive organizations, there are basic differences between the underlying philosophies of TQM and BPR. While TQM refers to programs designed to emphasize and achieve incremental improvements in work methods and procedures over an undefined period of time, BPR deals with discrete measures that are designed to achieve work designs that are altered radically and significantly improved in a specific time frame (Davenport, 1993: Malhotra, 1998). As a way to achieve immediate short-term results many organizations adopted aggressive TQM programs in the 1990s. It was this interest and use in TQM that led many organizations to also employ BPR analysis systems (Teng et al., 1994). As many organizations have found there exists a number of apparent parallels between the concepts of BPR and TQM, suggesting a degree of convergence between them (Valentine \& Knights, 1998). While several empirical studies have shown that TQM has certainly achieved efficient and improved work methods that have created competitive advantages for the organizations using it, the results also pointed to the need for something more in terms of radical organization redesign and altered work procedures (Powell, 1995; Hendricks \& Singhal, 1997).

Organizations of the twenty-first century have recently begun to realize that more needs to be done to achieve new work process paradigms that BPR may best deliver. Those who are true advocates of BPR believe that it is a system that requires a complete examination of an organization's roots to achieve changes at the paradigm shift level that achieve reinvention, not incremental change (Muthu et al., 1999).

\section{BPR and Job Redesign}

A literature review developed by O'Neill and Sohol (1999) made it clear that there are numerous and varied definitions of BPR. Davenport and Short (1990) offered a very narrow view of BPR which they believed involved the analysis of work flow and processes within and between organizations. On the other hand, Hammer and Champy (1993) provided a more widely known and encompassing manifesto which was grounded in the idea of complete reevaluation of business processes that result in radical change through the use of information technologies (IT). While the collective works of Hammer and Champy, either in cooperation with each other or done separately, have provided the spotlight on the BPR concept and gave the movement consistent momentum, others have made significant contributions to the better understanding of the field. Lowenthal (1994) stated the belief that any BPR analysis to be undertaken on the redesign of organizational processes and structure should focus on core competencies as a key element of improving performance. In addition, Teng et al. (1994) defined BPR as critical analysis and radical change that creates significant improvements in performance measures. While it can easily be acknowledged that many have offered their views and definitions of BPR, the basic idea relies on the focus of 
the sequence of activities which form the processes of business practice related to both the horizontal flow and the vertical grouping sometimes called functional silos (Childe et al., 1994). The organizations that have undertaken BPR in a big way have achieved the significant benefits of efficiency, competitive advantage and being in the position to encourage continuous improvement. Although many positive outcomes have been achieved through BPR the persistent myth is that BPR really means downsizing and outsourcing that leaves employees overworked and demoralized (Champy, 2006). While it is acknowledged that any change process can bring with it unintended consequences the challenge for effective BPR nonetheless requires more business and management mastery than ever before to overcome organizational inertia and achieve success. Therefore, one of the biggest obstacles to effective BPR has been the clinging to business as usual as unfounded fear.

Hammer and Champy (1993) discussed the idea that most organizations believed that things were generally going in the right direction as long as they could survive in the marketplace by finding the correct product at the right time. The notion of a total revamping of both horizontal and vertical business processes was never entertained. In addition, while the basic processes remained in place the addition of technology such as the influx of computers in the 1980s did little than reinforce outdated and ineffective work procedures. The introduction of new technology only marginally improved efficiency and productivity and failed to provide significant advancements that redesigned systems could have afforded. It is important to note that business and economic survival may now rely more on designing comprehensive innovative systems based on untried and risky ideas that are truly radical in nature versus the concept of slowly evolving and predictable standards.

\section{Information Technology as an Enabler}

Over the decades it has become evident that one of the most important ways to facilitate effective organization redesign through process engineering in organizations is through the use of information technology (IT) as an enabler of change. In fact, some have been willing to go beyond that by saying that IT is not only a key enabler of change, but also an initiator and a facilitator (Hammer, 1990; Chan, 2000). However, while IT played a significant role in changes in the nature of work responsibilities in organizations, the results achieved over the years appear to be more often than not to be slightly incremental and linear in nature. In other words the momentum of traditional business practices developed over the years overshadowed any ability of technology to shift work methods in a different direction or onto another plane. While Davenport (1993) agreed that information technology did indeed change work methods in terms of its nature, quality, speed and location that led to a reduced need for human labor, multi decade lags between adoption and significant redesign existed. While inventions of the nineteenth and twentieth centuries such as the telegraph and telephone were well suited to expedite the business demands of the time, they did very little to actually change business practices in an immediate way (Yates, 1989). However, after decades of the simplistic use of the telephone, the insight of the concept of call/contact centers revolutionized elements of the service industry into high growth, multi-billion dollar industries (Koole \& Mandelbaum, 2002). Therefore, more was needed than just innovation which was enabled by technology. What was needed and was seen to evolve eventually was a philosophy that technology should be a supportive supplement to go along with a drive to improve work processes and the overall system. Friedman (2005) believed that the full extent of his ten "world flatteners" were only truly employed after there was an emergence of managers, innovators, technology specialists and workers who were comfortable with the horizontal collaboration and value creation processes developed by these new ideas and technological advancements. Therefore, both ideas such as BPR and IT should work in tandem to achieve desired radical redesigns of work processes and structure based on a comprehensive and coherent strategy and goals. It is generally believed that change efforts should never be driven by technological goals alone (Manganelli, 1993). While the idea to continually introduce technological advancements that became essential elements in work methods was desirable because of their usefulness and usability, the concept of BPR was seen as a way to more fully capitalize on them as enablers for process innovation (Davenport, 1993). For example, productivity that has been achieved from computers is really a function of their combination with new business processes and new types of skills that go with them versus the fact that they are readily available for various applications (Friedman, 2005). 


\section{The Need for Vertical Redesign}

The introduction of various elements of IT into business office processes made the productive outcomes increasingly more efficient. Although the overall result was the same, the way it was produced had changed. Work that may have required a high degree of cooperation and coordination in the past could now be performed unilaterally with a high degree of efficiency and effectiveness. The need to separately compose, edit, analyze and complete a typed document involving several employees which usually included a typist/secretary became less likely (Chan, 2000). Unfortunately because this transformation process was taking place at such a minimally incremental rate, the managers with the authority and expertise to fully leverage this phenomenon did little to change the work process status quo which ultimately led to shift in job responsibilities in the typical office without the associated redefinition of job descriptions and designs. Therefore, while there was a continued subtle shift in the use of resources in terms of type and quantity, the job titles and associated perceptions of responsibility remained stagnant.

Whether human resource professionals realize it or not, many of the jobs occupied by their organization's professional employees have been significantly redesigned without even really trying to do so or at least in the ways intended. In a very subtle way over the last several decades both the development and the demand for improved technology within organizations made these changes inevitable. We all know how technology has made us more productive as our basic job duties have changed and we are familiar with how job holders routinely abandon outdated work processes for those that are more efficient and demanding. What we don't realize is that technology changes go beyond merely replacing old equipment with updated versions. Responding to the demands of changing technological needs also affects job and position expectations.

For instance, those of us in the workforce for the past 30 years can easily recall how computers replaced typewriters and the resulting struggle of adapting to the change. We also now acknowledge the ultimate realization of how well the new resources are so much better than the equipment that had been used for many decades for many jobs in organizations. Even though the change in job duties was slow and evolutionary because of fear and habit, no one disputes the significant and lasting benefits of today's information processing methods. The assumption over the years was that the associated formal modifications to relevant job descriptions and specifications caused by changes in technology followed close behind with the normal work of refining and fine tuning. The reality is that the impact of these changes was largely overlooked. This can be seen by examining the jobs directly affected as well as those jobs not previously directly affected and how these changes resonated in all directions in areas beyond the duties of those jobs where new technology was directly introduced. The realization is that there was and is a domino effect that impacted the performance of many different types of jobs. While some studies have acknowledged how technology has changed the human resource profession, the direct impact on things such as job and worker expectations still need to be further analyzed in depth (Leonard, 2000).

The fact remains that while many challenges are being seen and dealt with in the human resource profession in a variety of functional areas and activities including job requirements, the debate still continues whether or not job descriptions are needed or not. On the one hand the traditional view is still strongly held that job descriptions serve a valuable function in the areas of position responsibilities, performance reviews, compensation and in situations involving formal interpersonal relationships. Concise job descriptions do significantly reduce uncertainty in a job holder's conception of expected duties and responsibilities, end petty employee frictions and help managers be more focused on job outcomes versus being a constant force of oversight and being a referee (Doucette, 2002). On the other hand, many believe that while traditional job descriptions may outline, clarify and reinforce required job duties they also get in the way of encouraging employee initiative and flexibility. In addition to stating job duties they may more often than not be written to address legal issues to help insure the application of objective standards to various types of employment decisions (Leonard, 2000).

The ultimate outcome should not be a question of whether or not job descriptions remain or not, the real issue is how we can move forward to intelligently and efficiently design jobs descriptions that achieve the delicate balance between organizational demands for success and 
still maintain job expectations that are challenging, flexible and encourage employee initiative and adaptability. The realization that information technology can be an effective enabler of improved business processes creates new demands on the jobs in the workplace. The need to redefine positions to ensure maximum flexibility and to eliminate employees' downtime becomes the main goal (Caswell, 1995). Some organizations have gone as far as identifying the driving forces that make strategic job redesign a necessity to respond to technological challenges. These forces include issues related to the diversification and convergence of technology, the increased demand for educational access and changes in instruction and changing demands in the workplace (Swan \& Giunta, 1994).

\section{Redesigning Job Descriptions}

A basic purpose of reengineering and job redesign is to improve the procedures of the organization through effective problem-solving and increased adaptability to changing environmental conditions. While the desired outcomes are admirable and highly desired, many managers have found that they lacked sufficient data, information and adequate guides to pursue their efforts of redesign (Douglas, 1999). In recent decades the Job Characteristics Model of Hackman and Oldham (1976) has been a significant underlying idea of why job redesign should be conducted. The basic notion is that redesigned jobs not only hold out the promise of increases in productivity and quality but also more empowered employees in the workplace. In light of this organizations have been working to develop new ways to gain the most advantage from the combination of human resources of the organizational social system with technical elements of the traditional machine model (Neal \& Tromley, 1995).

Job redesign does require new job requirements, tasks, knowledge, skills and abilities that can create negative consequences such as anxieties over new and different job duties, increased work loads and perceived violations of the psychological contract (Badren \& Kafafy, 2008; Barnett et al., 2004). This could explain why efforts of job redesign have not been seen to keep pace with information technology advancements. The ultimate success of business process and job redesign depends on the ability of workers to learn new ways of doing their work through effective transfer of learning (Fadel et al., 2005). Workers who better understand redesigned jobs should then be more able to see the benefits of increased output that reinforce the hoped for positive attitudes of employees.

Preparing job descriptions that at a basic level include tasks and duties that employees are expected to perform should really be not in dispute. Some expectations of job performance are desirable and helpful in the overall scheme of things. The shift in the area of the job design paradigm comes to pass in acknowledging the outcomes for which job incumbents will be held accountable. In a changing business environment responsibilities and priorities can change very rapidly (Zarowin, 2005). Therefore, the issue becomes how job redesign can support individual and organizational success through the monitoring of the achievement of predetermined job outcomes as facilitated by business process reengineering.

The slow evolution has been to move away from traditional job descriptions which are skills-based to those job roles which concentrate on broader abilities and successful behaviors of better performers which are outcome oriented and may be more easily modified as technological changes occur (Joinson, 200I). In other words, the successful performance of the job may no longer only rely on job knowledge to perform specific duties, but rather on how the job holder acquires the knowledge to continue to be proficient in their job performance. Therefore, as the duties and responsibilities of a position change, the job holder seeks methods of continuous improvement to stay ahead of the curve and to be constantly open to opportunities in and outside of their job areas to get needed activities completed successfully. The expectation is that these role descriptions may be a way to confirm that all employees are expected to step forward where needed and to learn a wider set of skills to serve the greater good of the overall organization (Leonard, 2000). A somewhat recent study in France (Meriot, 2005) reported on how job and competence descriptions have made those in human resource development realize the far reaching implications in the associated function of employee training and development. In order to define what a competence description requires as far as successful job performance, a concerted effort to modify the preparation and training for the position is first needed to meet overall organizational goals. 
An interesting point to note is that the changes in how job description are to be developed in the future have the common point of reference which is the role of technology in the performance of jobs. As has been mentioned, every job has been impacted by the role of technology to some degree. There is a full range of outcomes as a result of technological change and job performance. Professions such as information based jobs, telecommunications, the nursing profession, accounting, engineering among others are on the cutting edge of job redesign (Armitage \& Shepherd, 2005). Since all jobs rely on the use of equipment and information technologies to some extent, even the jobs which have traditionally been not too highly technical in the past have been transformed whereby ultimate success not only relies on the use of ever changing technology but also on the ongoing realization staying ahead of the training and learning curve.

\section{Areas of Impact}

Beyond the changes seen in the specific performance of positions throughout a variety of professions being effected by the upgrade of technical skills, pressures have been building for years that have had an impact on various areas of the organization. The main areas that have felt the impact related to the changes in job design brought about by technological forces are personal growth and satisfaction, position responsibilities and economics as seen in Table I.

\section{Personal Growth and Satisfaction}

When it comes to personal growth and satisfaction a gradual shift in job redesign has probably achieved the most desirable results. A slow to moderate shift has allowed the employee time to adjust and thereby minimized reductions in job meaningfulness. In addition, guarantees of sufficient organizational support have provided opportunities for reinforcing training and job rehearsing (Rintala, 2005).

Technology induced changes in job descriptions and job skills have been acknowledged and adapted to through the experiences of the job holder. As might be expected, changes introduced in the workplace have been greeted with feelings of interest and excitement as well as fear and anxiety. For those who have felt uneasy, the shift to a newer set of job expectations has been extremely difficult or never occurred at all (Martinsons \& Cheung, 200I).
However, while many redesign initiatives have added to job responsibilities, required functional job retooling and the necessity to work with a variety of new employees from different departments, the chance of greater position autonomy has resulted in a feeling of more control over their workplace and the key events of success (Greenberg \& Grunberg, 2003). The desirable outcome has been that the job holder not only accepted the changes but actually saw them as a challenge to perform and continually improve their skill set. A supportive response on the part of the organization in terms of positive personnel decisions such as promotional opportunities, increases in merit and supportive recognition has reinforced these behaviors and associated outcomes.

\section{Position Responsibilities}

Redesigned job responsibilities that bring greater control and autonomy are being achieved through a greater participation in decision making at all levels. The process of job redesign in essence is facilitating a climate of delegation. A tradeoff of sorts is occurring whereby technology now allows a person in a professional or managerial position to perform the tasks once done for them by those at lower levels and in turn the lower level position is now free to pursue activities that require judgment and decision making skills. A valuable side effect is also achieved. Increased feelings of control and more participation in decision making may reduce or prevent burnout because employees have the opportunity to minimize conflicts and now have the power to achieve desirable work related outcomes (Wall \& Parker, 1998).

\section{Organizational Development}

Successful Organizational Development should include a holistic view of the organization, an acknowledgement of attempting to achieve simultaneous changes throughout the organization, a dynamic and long-term perspective and attention paid to redesigning and further developing the work to be done (Gunasekaran \& Nath, 1997). A key ingredient to position and organization development is the existence of informed leadership to have a vision, interpretation and the ability to communicate the value of redesigned positions. In addition, to achieve sustained results the organization must incorporate supportive training and clear linkages between performance and reward systems. 


\section{Economics}

There has always been a great deal of pressure to control administrative costs within areas of organizations where labor intensive cost structures exist (Swan \& Giunta, 1994). The current economic conditions and realities of the increased current emphasis on controlling labor costs obviously acts as a significant reminder that any changes made to the requirements of any job should not increase costs to the organization. If changes made in job and position descriptions added costs without significant value, the result would be to discourage any further developments in this area. Key outcomes of each area of impact that result from technology driven job redesign are found in Table I.

\begin{tabular}{|c|c|}
\hline Area of Impact & Outcomes \\
\hline \multirow[t]{6}{*}{ Personal Growth and Satisfaction } & Job meaningfulness \\
\hline & Reinforcing training and job \\
\hline & rehearsal \\
\hline & Functional position retooling \\
\hline & Perceived control and autonomy \\
\hline & Promotion and merit opportunities \\
\hline \multirow[t]{5}{*}{ Position Responsibilities } & Participation in decision making \\
\hline & Facilitation of delegation \\
\hline & Required judgment \\
\hline & Reduction and prevention of \\
\hline & Burnout \\
\hline \multirow[t]{4}{*}{ Organizational Development } & Leadership \\
\hline & Training \\
\hline & Monitoring and Appraisal \\
\hline & Rewards Systems \\
\hline \multirow[t]{4}{*}{ Economics } & Long run reduced labor costs \\
\hline & Job consolidations and created \\
\hline & positions \\
\hline & Skill set cost absorption \\
\hline
\end{tabular}

Table I. Job Redesign and Areas of Impact

The truth of the matter is that the required skill sets added to jobs in the administrative area have actually been absorbed without great fanfare. The standard practice of using advances in personal computer technology as a part of job performance proves that, for the most part, the training needed to apply word and data processing skills was and is being largely underwritten by the job holder. The transfer of the required performance of these additional duties and the associated skills to a professional job holder has allowed organizational positions such as secretaries to be assigned and pursue more administrative duties. Therefore, the eventual job redesign and reclassification for employees in these types of jobs begs the question, will redefined positions with "better sounding" titles and additional responsibilities command higher wages in the market? The answer probably lies with the fact that organizations will probably continue to expect higher job requirements but will not overtly change job titles or their methods of recruiting. The labor market in this area remains strong with significant pressures to more 
accurately reflect the true realities of job requirements for these job titles. Another fact that should not be ignored is the effect of long standing stereotyping associated with these jobs. Well entrenched beliefs change very slowly. Just ask the secretaries through the years who took the initiative to earn higher degrees beyond their job requirements and their rate of success in moving up their company's corporate ladder or overcoming the established stereotype. The truth of the matter is that in order to be perceived more accurately in terms of qualifications and added value to the organization they generally found it was easier to go back into the labor market and land a position more suited to their newly developed KSAs as compared to staying and fighting an overwhelming perception battle (Gatton, DuBois \& Faley, 1999).

\section{Summary}

The use of business process reengineering and the associated changes in information technologies in the workplace has been a double edged sword that requires a serious response to control and use them to the best advantage while at the same time opens up new possibilities of extending horizons of achievement. New and useful techniques offered by technological advances in a broad range of professions in business, health care, management information systems and academics has been able to achieve in a subtle way what may have been difficult to achieve in a more direct and above board manner which is the revising of job descriptions and requirements of professional employees and their support staffs. Technological advances in various types of equipment such as computers allow for more hands on work in positions where a separation of duties once occurred. Look around and stop for a moment to observe what takes place everyday in offices throughout the world and try to remember what it was like before we had computers with user friendly operating systems. The introduction of this type of technology, along with countless others, has changed job performance requirements forever. What cutting edge industry or organization has positions of responsibility and support without having state-of-the art technology available? When is the last time you or someone else witnessed an office without something as basic as a computer? Their de facto presence guarantees jobs performed in a way quite different from only a decade or so ago. Therefore, job descriptions are not fading away as some would advocate but rather they are being further developed and modified to acknowledge and accommodate changes in job requirements brought on by the fact that information technology is indeed an enabler of business process reengineering.

\section{References}

ARMITAGE, M., Shepherd, S. (2005). A new professional in the healthcare workforce: role, training, assessment and regulation. Clinical Medicine, 5(4), 3 II-324.

BADRAN, M., Kafafy, J. (2008). The effect of job redesign on job satisfaction, resilience, commitment and flexibility: the case of an Egyptian public sector bank. International Journal of Business Research, June, I-18.

BARNETT, R., Gordon, J., Gareis, K., Morgan, C. (2004). Unintended consequences of job redesign. Community Work \& Family, 7(2), 227-246.

CASWELL, J. (1995). Going virtual: how we did it - an accounting firm. Journal of Accountancy, 180(6), 64-67.

CHAMPY, J. (2006). People and Process. ACM Queue, 4(5), 35-38.

CHAN, S. (2000). Information technology in business processes. Business Process Management Journal, 6(3), 224237.

CHILDE, S.J., Maull, R.S.,, Bennett, J. (1994). Frameworks for Understanding Business Process Re-engineering. International Journal of Operations \& Production Management, 4(12), 22-34.

DAVENPORT, T. (1993). Process Innovation: Reengineering Working through InformationTechnology. Harvard Business School Press, Boston.

DAVENPORT, T., Short, J. (1990). The new industrial engineering: information technology and business process redesign, Sloan Management Review, 3 I (4), I I-27.

DOUCETTE, N. (2002). That's not my job. Rough Notes, I45, 40-45.

DOUGLAS, C. (1999). Organization Redesign: The Current State and Projected Trends. Management Decision, 37(8), 62I-627. 
FADEL, K., Brown, S., Tanniru, M. (2008). A Theoretical Framework for Knowledge Transfer in Process Redesign, The DATA BASE for Advances in Information Systems, 39(3), 21-39.

FRIEDMAN, T. (2005). The World is Flat: A Brief History of the Twentieth-First Century, Straus and Giroux, Farrar, New York.

GATTON, D., DuBois, C., Faley, R. (1999). The effects of organizational context on occupational genderstereotyping. Sex Roles: A Journal of Research, 40(7/8), 567582.

GREENBERG, E. \& Grunberg, L. (2003). The Changing American Workplace and the Sense of Mastery: Assessing the Impacts of Downsizing, Job Redesign and Teaming. Institute of Behavioral Science, Working Paper. PEC 2003-006.

GUNASEKARAN, A, Nath, B. (1997). The role of information technology in business process reengineering. International Journal of Production Economics, 50(2/3), 91-104.

HACKMAN, R., Oldham, G. (1976). Motivation through the Design of Work: Test of a Theory. Organizational Behavior and Human Performance, 1976, I6(2), 250-279.

HAMMER, M. (1990). Reengineering Work: Don't automate, obliterate. Harvard Business Review, 69(4), 104II2.

HAMMER, M. \& Champy, J. (1993). Reengineering the Corporation: A Manifesto for Business Revolution. Harper Business, New York.

HENDRICKS, K., Singhal, V. (1997). Does Implementing an Effective TQM Program Actually Improve Operating Performance? Empirical Evidence from Firms that Have Won Quality Awards. Management Science, 43(9), 12581274.

JOINSON, C. (200I). Refocusing Job Descriptions. HR Magazine, 46(I), 66-72.

KOOLE, G., Mandelbaum, A. (2002). Queuing Models of Call Centers: An Introduction. Annals of Operations Research, II3, 4I-59.
LEONARD, S. (2000). The Demise of Job Descriptions. HR Magazine, 45(8), 184.

LOWENTHAL, J. N. (1994) Reengineering the Organization: A Step-By-Step Approach to Corporate Revitalization, ASQC Quality Press, Milwaukee.

MALHOTRA, Y. (1998). Business Process Redesign: An Overview. IEEE Engineering Management Review, 26(3). http://www.brint.com/papers/bpr.htm (accessed 0I/28/09)

MANGANELLI, R. (1993). Define 're-engineer'. Computerworld, 27(29), 86-7.

MARTINSONS, M., Cheung, C. (2001). The Impact of Emerging Practices on IS Specialists: Perceptions, Attitudes and Role Changes in Hong Kong. Information and Management, 38(3), 167-183.

MERIOT, S. A. (2005). One or Several Models for Competence Descriptions: Does It Matter? Human Resource Quarterly, 16(2), 285-292.

MUTHU, S., Whitman, L. \& Cheraghi, S. H. (1999). Business Process Reengineering: A Consolidated Methodology. Proceedings of the 4th Annual International Conference on Industrial Engineering Theory, Applications and Practice, San Antonio, Texas,

NEIL, J. A., Tromley, C. L. (1995). From Incremental Change to Retrofit: Creating High Performance Work Systems. Academy of Management Executive, 9, 42-53.

O'NEILL, P., Sohol, A. (1999). Business Process Reengineering: A review of recent literature. Technovation, 19, 57|-58I.

POWELL, T. C. (1995). Total Quality Management as Competitive Advantage: A Review and Empirical Study. Strategic Management Journal, I6(I), 15-37.

RINTALA, N. (2005). Technological Change and Job Redesign: Implications for the Quality of Working Life. Espoo, Finland: Helsinki University of Technology, Doctoral Dissertation Series 2005/2.

SWAN, E. , Giunta, C. (1994). Organizational Effectiveness and Changing Job Design in the Information Technology Community. CAUSE/EFFECT, I7(2), 36-44. 
TENG, J., Grover, V., Fiedler, K. (1994). Re-designing business processes using information technology, Long Range Planning, 27(I), 95-106.

VALENTINE, R., Knights, D. (1998). TQM and BPR - can you spot the difference? Personnel Review, 27(I), 78-85.

WALL, T., Parker, S. (1998). Work and Job Design: Organizing Work to Promote Well-Being and Effectiveness. SAGE Publications, Thousand Oaks.

YATES, J. (1989). Control Through Communication: The Rise of System in American Management. Johns Hopkins University Press, Baltimore.

ZAROWIN, S. (2005). It's All in the Details. Journal of Accountancy, 200(I), I8.

\section{About the Author}

David M. Savino is an Associate Professor of Management at the James F. Dicke College of Business Administration at Ohio Northern University in Ada, Ohio. He teaches courses in Management in the areas of Organizational Behavior and Human Resources. His research interests include organizational change, job requirements, labor relations, leadership and decision-making. He has published articles in several journals including Journal of the North American Management Society, Employee Relations Law Journal, Labor Law Journal and the Journal of Management History. 